\title{
EL RECONOCIMIENTO DEL PERJUICIO ECOLÓGICO EN DERECHO FRANCÉS
}

\author{
CHAHINAZE HASNAOUI \\ Doctoranda \\ Universidad de Artois \\ Universidad de Murcia
}

\begin{abstract}
RESUMEN: Se analiza el reconocimiento del perjuicio ecológico en Francia como resultado de un largo proceso de construcción jurisprudencial y doctrinal. Para ello se toma como punto de partida el desastre del Erika, un petrolero cargado de 31000 toneladas de fuel que se partió en las aguas bretonas, causando una marea negra que alcanzó más de 400 kilómetros de costa francesa. Se estudian las distintas decisiones de los tribunales implicados en el juicio de esta catástrofe y las distinciones que se establecen entre perjuicios subjetivos (intereses patrimoniales y extrapatrimoniales de las personas) y objetivos (daños al ambiente natural).
\end{abstract}

PALABRAS CLAVE: perjuicio ecológico, prevención del daño, reparación del daño.

ABSTRACT: The recognition of the ecologic damage in France is analysed as a result long process of jurisprudential and doctrinal construction. For that, the Erika disaster is taken as a starting point, an oil tanker loaded with 31,000 tons of fuel which broke off in Breton waters, causing an oil slick which affected more than 400 kilometres of French coast. The different court's decision involved in the trial of this catastrophe, as well as the difference established between subjective damages (patrimonial and extra patrimonial interest of the people) and objective damage (environmental damage) have been studied.

KEYWORDS: environmental damage, damage prevention, damage repair.

SUMARIO: I. INTRODUCCIÓN - II. LA CONSAGRACIÓN LEGISLATIVA DE UNA NOCIÓN JURISPRUDENCIAL - II.1 La obligación de reparar un perjuicio ecológico - II.2 La prevención del perjuicio ecológico impuesta por la ley - III. UNA NORMATIVA CON APLICACIONES INCOMPLETAS - III.1 La reparación compleja del daño ecológico puro - III.2 La legitimidad de los solicitantes- IV. CONCLUSIONES - V. REFERENCIAS BIBLIOGRÁFICAS.

\section{INTRODUCCIÓN}

El reconocimiento del perjuicio ecológico en Francia ha sido el resultado de un proceso largo de construcción jurisprudencial y doctrinal, que se concluyó por la adopción de una ley en 2016, consagrando tal perjuicio y sus modos de reparación.

Todo empezó cuando el Erika, un petrolero cargado de 31000 toneladas de fuel se rompió en las aguas bretonas, causando una marea negra que alcanzó más de 400 kilómetros de costa francesa, y la contaminación de 74000 pájaros. Se necesitó 13 años de procedimientos 
hasta que llegó la sentencia del Tribunal Supremo del 25 de septiembre de 2012, para que asociaciones, regiones y ciudades obtengan reparación del daño causado por ese naufragio ${ }^{1}$.

Las numerosas decisiones de los tribunales implicados en el juicio de esta catástrofe son interesantes por los principios puestos de relieve poco a poco, como la sentencia del tribunal de apelación del 30 de marzo de 2010 en la cual los jueces adoptaron un razonamiento confirmado por el Tribunal Supremo después. En efecto, distinguieron los perjuicios subjetivos y objetivos : los primeros perjudican los intereses patrimoniales y extrapatrimoniales de las personas y serán considerados por el solicitante a la reparación, mientras que los segundos han sido definidos como "los daños no despreciables al ambiente natural, o sea, el aire, el atmosfera, el agua, los suelos, las tierras, los paisajes, los sitios naturales, la biodiversidad y la interacción de estos elementos, que no tiene repercusiones sobre un interés humano en particular, sino que afecta un interés colectivo legítimo", y serán apreciados de manera "despersonalizada"2.

Tal motivación mostro que se tomaron en cuenta los perjuicios por allá del perjuicio personal solo, distanciándose de la acepción general de responsabilidad en derecho civil.

Así evocado en más de 190 sentencias $^{3}$ y decisiones, el perjuicio ecológico está consagrado en el Código civil tras la promulgación de la ley sobre la biodiversidad de agosto 2016, basada sobre el informe Jegouzo, producido por un grupo de juristas.

El grupo de reflexión, constituido de profesores y especialistas de derecho ambiental, tenía como objetivo la inclusión dentro del código civil de un "perjuicio ecológico colectivo" aclarando por la misma ocasión el régimen de responsabilidad ambiental para favorecer la prevención de daños ecológicos. Diez proposiciones fueron formuladas:

1) la definición del perjuicio ecológico y la creación de un régimen de reparación del daño ambiental en el código civil

2) el reforzamiento de la prevención de danos ambientales

3) ampliar la posibilidad de recursos para obtener la reparación de danos ecológicos

4) la creación de una alta autoridad ambiental garantizando la reparación

5) la previsión de reglas de prescripción especificas

6) especializar jueces en la reparación de perjuicios ambientales

7) crear condiciones de peritajes especiales e independientes en materia ambiental

8) la consagración del principio de reparación en especie del perjuicio ecológico

9) la creación de un fundo de reparación ambiental

10) la consagración de la multa civil

\footnotetext{
${ }^{1}$ Tal reconocimiento fue favorecido por una decisión del Consejo Constitucional de 2011 que admitió una obligación de vigilancia de los posibles danos causados al medio ambiente por un individuo quien incurre en responsabilidad civil.

${ }^{2}$ V. Ravit, Réflexions sur le destin du préjudice écologique “pur”, Dalloz, 2012.

${ }^{3}$ CA Bordeaux, 13 de enero de 2006, n05/00567: reconoce "el perjuicio subido por la fauna y flora marinas [...]"
} 
Así el artículo 2 de la ley de 2016 impone que "toda persona responsable de un perjuicio ecológico tiene que repararlo".

Desde el fin de los años setenta, muchos autores han abogado a favor de un reconocimiento doble del perjuicio ecológico: un perjuicio causado a elementos naturales como tal (perjuicio ecológico puro), y otro causado a personas y bienes (perjuicio ecológico derivado). Este razonamiento conduce a considerar perjuicios "subjetivos" y "objetivos":

Se entiende el perjuicio de dos maneras: por una parte, el perjuicio ecológico "derivado" que permite de tomar en cuenta las consecuencias de una vulneración del medio ambiente sobre personas y sus bienes (perjuicios patrimonios, extra-patrimonios y físicos). Para saber si el perjuicio ecológico derivado se aplica tiene que cumplir tres condiciones: debe ser directo, personal y cierto

Por otra parte, el prejuicio ecológico puro se entiende en el sentido estricto, por que cobra las hipótesis de vulneraciones al medio ambiente, independientemente de las repercusiones del daño sobre las personas y/o bienes.

La adopción de tal ley sobre el prejuicio ecológico resultaba de un triple imperativo: la consolidación de la jurisprudencia, la estabilización del régimen de reparación aplicable al prejuicio ecológico y la clarificación de las reglas adaptadas a las particularidades de un prejuicio objetivo y colectivo.

El régimen de responsabilidad ambiental en derecho francés resulta de la transposición de la directiva europea 2004/35/CE del 21 de mayo de 2004. Las disposiciones de la ley francesa se pueden encontrar en el Código del medio ambiente a los artículos L. 160-1 y siguientes y R. 161-1 y siguientes. Sabiendo que el derecho de la responsabilidad civil debía contribuir a reforzar la protección del medio ambiente con respeto a los retos económicos y sociales relacionados, reforzado por el derecho ambiental, se planteó la cuestión de la aplicación de esa normativa progresista en apariencia, pero mucho más compleja que aplicar en práctica.

La consagración legislativa de la noción jurisprudencial del perjuicio ecológico (I) conoce por desgracia una aplicación incompleta (II) que impone a los juristas el desarrollo de normas segundarias.

\section{LA CONSAGRACIÓN LEGISLATIVA DE UNA NOCIÓN JURISPRUDENCIAL}

A pesar de la ausencia de texto normativo imponiendo obligaciones relativas al tratamiento de un daño causado al medio ambiente, los jueces solían referirse a mecanismos de reparación clásicos del régimen de responsabilidad civil. Por lo tanto, empujado por reivindicaciones de la sociedad civil y actores de la protección del medio ambiente, el legislador tuvo que marcar de manera fuerte y simbólica la obligación de reparar un perjuicio ecológico (A), lo que hizo, a través de la ley sobre la biodiversidad. Tal texto permitió también de subrayar la necesidad de prevenir la comisión de cualquier daño ambiental: esa necesidad se convirtió en una obligación legal (B). 


\section{II.1 La obligación de reparar un perjuicio ecológico.}

El naufragio de Erika suscitó una emoción considerable en 1999, cuando, por la mañana de Navidad, Francia estuvo con unos 400 kilómetros de costas manchadas por el petróleo del buque. Los jueces que estudiaron las consecuencias jurídicas de la catástrofe no vacilaron en hacer obra creadora y en sobrepasar el obstáculo de la exigencia de perjuicio causado a "otro" del antiguo artículo 1382 del código Civil, para admitir el principio de la reparación del perjuicio ecológico, independientemente de toda repercusión sobre los sujetos de derecho. Así, como los jueces de primera instancia, el Tribunal Supremo dedicó, en su sentencia del 25 de septiembre de 2012, el carácter reparable de " la vulneración directa o indirecta llevada al medio ambiente", consolidando un movimiento jurisprudencial.

En 1982 el Tribunal Supremo acepto el principio de una reparación del perjuicio moral de una asociación de protección del medio ambiente como parte civil, tras la destrucción de una especie protegida por un cazador (caso del "oso canela").

También en 1985, el departamento corso vio su perjuicio moral reparado cuando litros de lodos rojos fueron derramados en sus costas por la sociedad Montedison. Los jueces consideraron que tal incidente perjudicó la imagen de marca de la isla.

El tribunal de apelación de Burdeos reconoció en 2006 el perjuicio ecológico como "el perjuicio sufrido por la flora y los invertebrados del medio acuático" ${ }^{4}$ tras la realización de obras ilícitas en un curso de agua que condujo a la desecación del rio.

El tribunal de Tours se basó sobre esta definición para condenar en 2008 los responsables de la muerte de miles de peces en la Loire, que derramaron productos químicos en un rio.

Estas decisiones no reconocen el perjuicio ecológico directamente causado al medio ambiente sino perjuicios derivados aguantados por sujetos de derecho: perjuicios económicos y mora.

El principio de reparación en derecho de la responsabilidad civil implica en efecto, que la víctima de un daño sea una persona, física o moral, pero dotada de la personalidad jurídica. No obstante, la naturaleza o medio ambiente, no dispone de tal calidad y resulta que su perjuicio no puede ser reparado de manera directa y propia.

El nuevo régimen de reparación del perjuicio ecológico indirectamente se encuentra reforzado por la colocación de la acción de grupo en materia medioambiental por la ley de modernización de la justicia del siglo XXI del 18 de noviembre de 2016. En efecto, el reconocimiento del hecho generador y del lazo de causalidad por el juez en el marco de la acción de grupo aprovechará necesariamente a los solicitantes a la acción en reparación del perjuicio ecológico puro. A continuación, la ley n ${ }^{\circ}$ 2008-757 del 1ero de agosto de 2008 sobre la responsabilidad ambiental transpuso en derecho francés la directiva europea 2004/35 del 4 de abril de 2004 e introdujo en el código del medio ambiente un nuevo régimen de policía para la prevención y la reparación de algunos daños causados al medio ambiente.

Ese arsenal normativo permite hoy en día, una mejora toma en cuenta del perjuicio ecológico por ser definido y dotado de un régimen jurídico propio.

\footnotetext{
${ }^{4}$ Tribunal de apelación de Burdeos, 13 de enero de 2006, nº5/00567
} 


\section{II.2 La prevención del perjuicio ecológico impuesta por la ley.}

Existe ahora una definición legal del daño ecológico, entendido como: "una vulneración no despreciable de los elementos o funcionamientos de los ecosistemas" y una responsabilidad preventiva ha sido reconocida: antes la supervención del daño y después.

La nueva ley aprobó la jurisprudencia existente admitiendo la reparación de "los gastos expuestos para prevenir la realización inminente de un daño, su agravación o para reducir sus consecuencias". Además, el legislador dio a los jueces la posibilidad de "prescribir medidas razonables propias a prevenirlo o a pararlo", si fueron solicitados por una persona presentando un interés a actuar.

En esta forma, el derecho a la reparación del prejuicio ecológico es precursor porque en el futuro, la acción preventiva podrá ser generalizada dentro de la reforma de la responsabilidad civil.

Otra particularidad reside en la facultad del juez de intervenir para impedir o parar la realización de un daño mientras tanto ese resulta de una decisión administrativa.

Tal prevención prevista por el régimen de responsabilidad ambienta se articula con el derecho de la responsabilidad civil, ya que las medidas de reparación pueden concernir el riesgo sanitario, tener consecuencias en los servicios ecológicos...

El articulo L162-2 del código del medio ambiente dispone que "una persona víctima de un perjuicio que resulta de un daño ambiental o de una amenaza inminente de tal daño, no puede pedir una reparación [sobre la base legal de la reparación del perjuicio ecológico "puro"]".

Significa que la reparación del perjuicio ecológico puro no puede poner en tela de juicio la reparación de perjuicios ecológicos derivados. La reparación de un perjuicio derivado no está condicionada al reconocimiento de un perjuicio ecológico puro, y cuando ambos sobrevienen, su reparación puede concordar de manera autónoma.

\section{UNA NORMATIVA CON APLICACIONES INCOMPLETAS}

La dicotomía teórica creada por la doctrina entre perjuicio ecológico "puro" y "derivado" implica una aplicación especial del régimen clásico de reparación, haciendo compleja la aprehensión en práctica del perjuicio ecológico puro, y de hecho, su reparación (A). A esta consideración se puede añadir la problemática en cuanto a la legitimidad de los solicitantes a la acción en justicia (B) ya que, tratando de la reparación de un bien común, hace falta impedir la multiplicación de recursos relativos al mismo caso por varias personas con intereses o/y objetos sociales diferentes.

\section{III.1 La reparación compleja del daño ecológico puro.}

Una de las dificultades de la aplicación de la reparación de tal perjuicio resulta de un constato simple: la naturaleza no tiene precio. 
En derecho positivo, el medio ambiente tiene el estatuto de bien común de la nación o de patrimonio común de la humanidad. Por lo tanto, no tener precio no significa que puede ser destruida libremente.

¡Otra dificultad reside en el hecho de que personas sean beneficiarias directas de la indemnización resulto de la reparación del perjuicio ecológico, que tiene una dimensión colectiva!

Según los principios clásicamente admitidos en responsabilidad civil, la simple constatación de una ofensa no es suficiente en sí para caracterizar un perjuicio indemnizable. El perjuicio debe además responder a ciertos criterios entre los cuales figura su carácter personal que supone que afecta a una persona o un patrimonio en particular.

La protección de los recursos naturales no rehace el interés personal, sino el interés general. Dos afirmaciones lo atestiguan: la primera según la cual la protección medioambiental es de interés general y la que hace recursos naturales un componente de un patrimonio común. El perjuicio ecológico puro posee sentado exógeno, unitario y objetivo que consiste exclusivamente en la ofensa del medio ambiente. Desde entonces, presenta un carácter impersonal (o "objetivo") en lo que concierne a la colectividad muy entera y lo que no puede ser exclusivamente relacionado con los intereses de una persona en particular, lo que se trate de una persona física o moral, pública o privada.

Parece fundamental identificar a las personas susceptibles de pedir una indemnización del prejuicio ecológico puro para evitar que sea reparado varias veces, lo que es contrario al principio de reparación integral. Para una asociación, la personalidad jurídica es instrumentalizada para servir más una preocupación comuna, que constituye el objeto social de una entidad jurídica nueva.

La inmensa mayoría de las técnicas de evaluación monetaria del perjuicio ecológico puro han sido soltados en la ocasión de la reparación de los daños causados por el vertimiento de hidrocarburos en mar. Pero las experiencias llevadas sobre este terreno testimonian dificultades que se ponen para la evaluación monetaria de todo perjuicio ecológico puro, cualquiera que sea su hecho generador.

Por desgracia, las numerosas exclusiones previstas por los textos - contaminaciones por hidrocarburo, accidentes nucleares - y de exoneraciones de responsabilidad limiten el alcance de este texto.

Además, la directiva del 21 de abril de 2004 plantea dos series de reservas a que sea comprometida la responsabilidad del autor.

Por una parte, reconoce muchas causas eximentes de responsabilidad ${ }^{5}$ y por otra parte instituye un régimen de doble responsabilidad: por falta (según la actividad) o falta limitada (según el tipo de daño).

\footnotetext{
${ }^{5}$ C. Hermon, La réparation du dommage écologique, les perspectives ouvertes par la directive du 21 avril 2004 , AJDA, 2004
} 
El perjuicio ecológico puro no puede ser evaluado a partir de valores de referencia preexistentes; hace falta aclarar de manera conceptual y metodológica sus contornos antes de establecer los modos de reparación pecuniaria.

El derecho de la responsabilidad civil tiene contornos demasiados vagos para tomar en cuenta y reparar de manera adecuada las ofensas al medio ambiente ${ }^{6}$.

De hecho, el régimen de la responsabilidad ambiental dispone en teoría de los elementos necesarios a la buena apreciación y gestión de siniestros ecológicos.

\section{III.2 La legitimidad de los solicitantes.}

La cuestión de la calidad y del interés de actuar en responsabilidad: el artículo 1248 del Código Civil dispone que " la acción en reparación del perjuicio ecológico es abierta a toda persona que tiene autoridad e interés en actuar, tal como el Estado, la Agencia francesa para la biodiversidad [creada por la ley sobre la biodiversidad], a las colectividades territoriales y a sus agrupamientos cuyo territorio le conciernen, así como los establecimientos públicos y las asociaciones aceptadas o creadas por lo menos desde hace cinco años a la fecha de introducción de la instancia que tienen como objeto la protección de la naturaleza y la defensa del medio ambiente".

Es decir que personas públicas como privadas podrán actuar si tienen la calidad y el interés requisitos por el texto de ley.

Es la reparación del perjuicio ecológico puro que interroga en cuanto a los potenciales solicitantes que pueden pedirla, ya que lleva unas dificultades relacionadas con su carácter impersonal, la posible concentración o dispersión de la reparación, el carácter no mercantil del perjuicio y la necesidad de una reparación en especie.

Varias entidades, cuyas personas físicas, se vieron reconocer un derecho a la reparación del perjuicio ecológico puro, sin embargo, planteó la cuestión de la reparación múltiple del mismo. Por ejemplo, un suelo contaminado en un terreno perteneciendo a una persona física que ve su flora y fauna exterminadas a pesar de que sean protegidas por ser especies amenazadas de desaparición, puede conducir asociaciones de protección del medio ambiente y el propietario del terreno a hacer un recurso, ya que ambos pueden presentar un interés legítimo a la reparación del perjuicio.

Entonces el reto de este tema consiste en tomar el riesgo de ver un mismo perjuicio reparado varias veces, de acuerdo con el principio de reparación integral de perjuicio ecológico puro.

El interés en actuar esta cierto cuando a la persona que actúa le concierne el perjuicio porque se encuentra sobre su territorio o porque el objeto de su formación es la protección medioambiental (el interés para las asociaciones es de tener un objeto social bastante ancho para incluir una multitud de acciones). Aquí, leemos un ensanche del recurso a la justicia.

Por consiguiente, el campo de aplicación del nuevo régimen se limita a los perjuicios todavía no reparables, sin volver sobre los hechos generadores de responsabilidad requeridos

\footnotetext{
${ }^{6}$ V. Ravit, Réflexions sur le destin du préjudice écologique “pur”, Dalloz, 2012.
} 
que quedan los de la falta, la guardia de la cosa y el hecho del prójimo. Esto significa que la reparación del perjuicio ecológico se limita a los casos de responsabilidad para falta. Así, un explotador podrá ser reconocido responsable de contaminación, a pesar de una autorización de su actividad, y esto, por aplicación del principio según el cual las autorizaciones administrativas son dadas a reserva del derecho de los terceros.

En materia ambiental, una contaminación puede provocar una vulneración de varios intereses privados o personales, pero según su extensión, también puede vulnerar el interés general, u orden público, cuando pone en tela de juicio medidas de protección, de valorización, de restauración y de gestión de recursos naturales (artículo L.110-1 del Código del medio ambiente); de hecho, constituye un perjuicio ecológico puro. ¿Entonces quién será lo más vulnerado o tendrá más interés en la reparación del dicho perjuicio?

El reconocimiento indirecto del perjuicio ecológico en las sentencias de primera instancia pasaba por la reparación del perjuicio colectivo calificado en la mayoría de los casos de "perjuicio moral". Es muy frecuente de ver asociaciones de protección del medio ambiente obtener esa reparación fundada sobre el articuloL.142-2 del código del medio ambiente, que define «una ofensa causada al interese colectivo que la asociación se dio por misión de defender".

En estas situaciones, el monto de la reparación es concertado y simbólico; entonces parece la reparación del daño ecológico tras la indemnización de un perjuicio moral inapropiada.

\section{CONCLUSIONES}

Hay que considerar el perjuicio ecológico en una perspectiva evolutiva. Su reconocimiento como la creación de su cuadro jurídico resultan de construcciones doctrinales y jurisprudenciales, y así se debe fortalecer la comprensión y reflexión sobre ese tema.

Cual sea el perfeccionamiento que ocurre en materia ambiental, debe ser la traducción de hechos concretos, definitivamente insertado en el proyecto social de cada sociedad.

La existencia de una ley no suplanta el trabajo jurisprudencial realizado hasta hoy; el profesor Motulsky decía "el derecho existe solo si está efectivo".

La toma en cuenta del perjuicio ecológico tiene que ser mejorada y esto pasa por la reforma de las normativas internacionales relativas a la indemnización de los danos causados por la actividad de transporte o de servicios marítimos. ${ }^{7}$

\section{REFERENCIAS BIBLIOGRÁFICAS}

- Bacache M., Préjudice écologique et responsabilité civile, La Semaine Juridique Edition Générale $\mathrm{n}^{\circ}$ 23, (2016).

\footnotetext{
${ }^{7}$ E. Banel, C. Bellord, Groupe de travail sur la réparation des préjudices écologiques, la reconnaissance légale du préjudice écologique, JCI, 2014.
} 
- BANEl E., BELlORD C., Groupe de travail sur la réparation des préjudices écologiques, la reconnaissance légale du préjudice écologique, JCI, (2014).

- Cayol A., Confirmation de l'indemnisation du préjudice écologique pur, Petites affiches, (2016).

- De MonTeCler M.-C., Dix propositions pour la réparation du préjudice écologique, AJDA, (2013).

- HeRMOn C., La réparation du dommage écologique, les perspectives ouvertes par la directive du 21 avril 2004, AJDA, (2004).

- Huglo C., Avocat pour l'environnement, LexisNexis, (2013).

- Huglo C., Affaire de l'Erika, propos introductifs au thème "Etat des lieux", JCI, (2014).

- JEGOUZO Y., Nomenclature des préjudices environnementaux, LGDJ, 2012.

- MARTin J., La réparation des atteintes à l'environnement in Les limites de la réparation du préjudice, Dalloz, (2009).

- MeKKI M., La réparation du préjudice écologique pur : pied de nez ou faux-NEZ ? Gazette du Palais n³4, (2016).

- NEYRET L., Introduction de la problématique. Le préjudice écologique: hier, aujourd'hui et demain, JCI, (2014).

- NeYRet L., Proposition de nomenclature des préjudices réparables en cas d'atteinte à l'environnement, Revue Environnement, (2009).

- NeYRET L., MARTin J. (dir.), Nomenclature des préjudices environnementaux, LGDJ, (2012).

- RAVIT V., Réflexions sur le destin du préjudice écologique "pur”, Dalloz, (2012).

- ROBERT J.-H., Naufrage de l'Erika: responsabilité de l'affréteur et reconnaissance du dommage écologique, RSC, (2008). 